\title{
Growth regulation of cow1 rice mutant seedlings by blue light
}

\author{
Chang-Hyo Goh · Suk-Min Ko $\cdot$ Hee-Yeon Park $\cdot$ Yeon-Ki Kim $\cdot$ Yong-Woo Kim • Young-joo Kim • \\ Hyeon-Jin Sun · Yong-Hwan Moon · Hyo-Yeon Lee
}

Received: 17 November 2010 / Accepted: 1 December 2010

(c) Korean Society for Plant Biotechnology

\begin{abstract}
We assessed whether the cowl mutant defects are associated with growth of Tos 17 and T-DNA insertional rice in blue light (BL). Growth of oscow1 mutants which encoded a member of the YUCCA protein family was retarded in BL. Root to shoot ratios of the mutants were reduced about 2 times lower in the absence of NAA and about 2.5 times lower in the presence of NAA; the shoot growth was not significantly changed by NAA addition. Photosynthetic activity of the mutants was however inhibited in high light. Pigment analysis showed significant difference between wild-type $(\mathrm{Chl} a: b=3.02)$ and mutants (3.84). Carotenoid contents of the mutants were also decreased considerably, implying the involvement of cowl in pigment formation. These findings lead us to suggest that the growth retardation of oscow 1 mutant plants by BL results from the difference of photosynthetic activity in part.
\end{abstract}

Keywords Chlorophyll $a$ fluorescence; OsCOW1; Photosynthesis; Plant growth; Rice

The first two authors made equal contributions to this manuscript. C.-H. Goh $(\bowtie)$

Citrus Breeding \& Agricultural Research Institute, Palmtree, Jeju 699-904, Korea

e-mail: changhyogoh@hanmail.net

S.-M. Ko • Y.-W. Kim • H.-J. Sun • H.-Y. Lee

Subtropical Horticulture Research Institute, Jeju National University, Jeju 690-756, Korea

H.-Y. Park • Y.-H. Moon

Division of Biological Sciences, Pusan National University, Busan 609-735, Korea

Y.-K. Kim

GreenGene Biotech, Myongji University, Yongin, 449-728, Korea

Y.-j. Kim

Jeju Biodiversity Research Institute, Jeju 697-943, Korea

H.-Y. Lee

Faculty of Biotechnology, Jeju National University, Jeju 690-756, Korea

\section{Introduction}

Auxin is an essential plant hormone that influences many aspects of plant growth and development including cell division, tropisms, apical dominance, senescence, abscission, and flowering (Davies et al. 1995). A recent report showed that gain-of- function mutant for Arabidopsis YUCCA5, a suppressor of ERECTA1, increased levels of free indole-3-acetic acid (IAA) and a phenotype of IAAoverproduction (Woodward et al. 2005). Additional reports showed that a dominant Arabidopsis and rice yucca produced elevated levels of endogenous auxin (Zaho et al. 2001; Yamamoto et al. 2007); YUCCA, a flavin monooxygenase (FMO)-like enzyme, catalyzes a key step in Arabidopsis tryptophan-dependent auxin biosynthesis (Zhao et al. 2001).

In relation to auxin levels of rice, OsYUCCA1 overexpressing plants produced high IAA levels, whereas antisense plants of the gene exhibited severe growth retardation (Cheng et al. 2006). Further recent study showed that lack of CONSTITUTUVELY WLTED 1 (OsCOWI) gene, a member of the rice YUCCA family, lowered root to shoot ratios with growth retardation (Woo et al. 2007). A proposed function for the YUCCA gene family in plants clearly appears to regulate the development processes by the elevation of auxin biosynthesis.

Auxin distinctively regulates the root growth and development. Increasing its root to shoot ratio is a plant strategy for restoring water homeostasis in response to the longterm imposition of mild water stress (Woo et al. 2007). Plants cannot move and are forced to grow where they germinate. Accordingly, they have evolved mechanisms to sense their environment and adjust their physiology and development to optimize growth. Plants are able to detect neighbor proximity using sensing and response systems 
based on the quality of ambient light and growth regulation (Fellner et al. 2003). Light influences plant development and may act in part by modifying responses to the hormone auxin, suggesting light regulation of auxin biosynthesis (Tian and Reed 2001). On the other hand, rapid synthesis of auxin via a tryptophan-dependent pathway is required for shade avoidance in plants (Tao et al. 2008). PhyB is the major phytochrome in light-grown plants and plays a predominant role in the shade avoidance response to far-red light (Ballare 1999). The blue light (BL) receptors termed cryptochromes mediate photomorphological responses in seed plants; cryptochrome light signals control plant development to suppress auxin sensitivity in the moss (Imaizumi et al. 2002). Therefore, further details on growth retardation of yucca mutant plants to $\mathrm{BL}$ are needed whether the phenotype could be differentially regulated.

In the present work, we show that oscowl mutant plants delay growth in a specific response to BL. We examine this growth pattern and determine how root growth and shoot to root ratios of oscow1 mutant seedlings are affected. We also determine whether photosynthetic activity in the leaves of oscowl mutant plants is inhibited under high light.

\section{Materials and methods}

Plant materials and growth conditions

Wild-type (Oryza sativa cv. Japonica, Hwayoung) and two oscowl mutant (Tos17 and T-DNA insertion) (Woo et al. 2007) rice seedlings were grown on half-strength MurashigeSkoog (MS) containing $0.2 \%(\mathrm{w} / \mathrm{v})$ phytagel and $3 \%$ sucrose for 10 days. For the analysis of root to shoot ratios, the media contained various auxins (IAA, 2,4-D, 1-NAA). Seedlings were cultured in a temperature-controlled growth chamber $\left(28 \pm 1^{\circ} \mathrm{C}\right)$ under continuous dark and blue light (BL, $40 \mu \mathrm{mol} \mathrm{m} \mathrm{m}^{-2} \mathrm{~s}^{-1}$ ) in a $16 / 8 \mathrm{~h} \mathrm{light/dark} \mathrm{cycle} \mathrm{using} \mathrm{a}$ LED system (GF-320s, Good Feeling, Sungnam, South Korea). BL was produced by light-emitting photodiodes (LED-B, maximum intensity 466 nm; Goodfeeling, Kyunggi, Korea).

Chlorophyll fluorescence analysis

For the analysis of rapid light response curves, chlorophyll fluorescence was measured using a MICROSCOPY IMAGING-PAM (Heinz Walz GmbH, Effeltrich, Germany) as described previously (Goh et al. 1999 Schreiber et al. 2007). The MICROSCOPY-PAM was operated using a Pentium II PC with WinControl software (Walz). In order to create rapid light response curves for cell photosynthesis, stepwise increases in the intensity of actinic light (AL) were applied in a series of $30 \mathrm{~s}$ pulses. A saturating light pulse (SP) was applied at the end of each illumination period. Quantum yield of the photochemical energy conversion in photosystem II (PS II) was estimated using the empirical fluorescence parameters $\left(\mathrm{F}_{\mathrm{m}^{\prime}}-\mathrm{F}\right) / \mathrm{F}_{\mathrm{m}^{\prime}}=\Delta \mathrm{F} / \mathrm{F}_{\mathrm{m}^{\prime}}$ (Genty et al. 1989) and the apparent relative electron transport rate (ETR), i.e., $\triangle F / F_{m} \times$ PPFD $\times c$ (where PPFD is the photosynthetic photon flux density of incident active radiation and the constant $\mathrm{c}$ corresponds to the absorption factor for the measurement; Schreiber et al. 1994). All experiments were performed at room temperature.

Leaf gas exchange measurements

Rates of net $\mathrm{CO}_{2}$ uptake by attached leaves were measured in an open gas exchange system (LCA2, ADC, Hoddesdon, UK) coupled to a mass spectrometer as described previously (Goh et al. 2004). In the chamber, leaf temperature was maintained at $25^{\circ} \mathrm{C}$ by a temperature controller (Prime Bio Chemical Co., Seoul, Korea). BL (200 $\left.\mu \mathrm{mol} \mathrm{m} \mathrm{s}^{-1}\right)$ was produced by a light-emitting photodiode (LED-B, maximum intensity at $466 \mathrm{~nm}$; Goodfeeling, Kyunggi, Korea). Air entering the Parkinson leaf chamber was conditioned at 40\% relative humidity and 370-380 $\mu \mathrm{l} \mathrm{l}^{-1}$

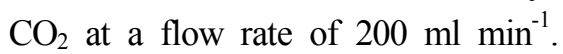

Pigment analysis

Pigment analysis was performed as described previously (Gilmore et al. 1991). The harvested leaves were frozen in liquid nitrogen and ground with a mortar and pestle in ice-cold acetone at $4^{\circ} \mathrm{C}$ in the dark. The pigment extracts were passed through a $0.2 \mu \mathrm{m}$ syringe filter and separation performed by HPLC system (HP 1100 series; Hewlett Packard, Waldbronn, Germany) using a Spherisorb ODS-1 column (Alltech, USA). Pigment concentrations were estimated using the conversion factors for the peak areas (in nanomoles), which were calculated for this solvent mixture by Gilmore and Yamamoto (Telfer 2005). 


\section{Results and discussion}

The Constitutively wilted 1 (COWI) gene, which encodes a member of the rice YUCCA protein family, was isolated and characterized in Tos17 (oscowl-2) and T-DNA insertional rice mutants (oscow1-1) (Woo et al. 2007). These mutants had a phenotype with rolled leaves, reduced leaf widths, and lower root to shoot ratios in natural light. On the other hand, plants grown at high densities perceived a decrease in the red to far-red (R:FR) ratio of incoming light, resulting from absorption of red light by canopy leaves and reflection of far-red light from neighboring plants (Tao et al. 2008). These changes in light quality can trigger a series of growth responses (Takano et al. 2001). For this reason, we analyzed plant growth in blue light (BL) to avoid factors affecting the maintenance of root to shoot ratios, such as phytochromes. BL alone significantly enhanced plant growth by BL receptors for example, phototropin in rice (Goh et al. 2009) and Arabidopsis (Takemiya et al. 2005).

In $\mathrm{BL}$ at $40 \mu \mathrm{mol} \mathrm{m} \mathrm{m}^{-2}$, it was significantly lower than that of wild-type (WT) seedlings (Fig. 1A). The fresh weight of 10-day-old seedlings was $0.164 \pm 0.008$ and $0.134 \pm 0.012 \mathrm{~g}$ for WT and oscowl mutant plants, respectively, showing about $20 \%$ inhibition in BL (Figure 1B). The growth of oscowl seedlings was similar to that of WT tested in the dark (Fig. 1C). To examine the effect of exogenous auxin on the oscowl mutant root growth, seeds of the WT and the oscowl mutant were germinated and grown in nutrient solution supplied with
$1 \mu \mathrm{M}$ of synthetic auxin analogue, 1-naphthnyl acetic acid (NAA), which affects root elongation (Zhuang et al. 2006). Root growth of oscowl mutants was decreased by $30-35 \%$ in comparison to WT seedlings in BL (Table 1) Treatment with NAA led to a greater decrease in root growth by $68 \%$ for WT and $43 \%$ for oscowl mutants, respectively, indicating that the mutants were less sensitive than the WT. Moreover, shoot growth of WT was significantly decreased by $64.4 \%$, whereas shoot growth of the mutants was not changed with the treatment of NAA. We suggest that the growth in these mutants is largely associated with root development in $\mathrm{BL}$

Since OsCOW1-mediated plant growth plays an important role in maintaining root to shoot ratios and, in turn, affects water homeostasis in rice (Woo et al. 2007), poor root development in oscow1 mutant seedlings (Fig. 1A, B) may affect metabolic activity underlying vegetative development. In addition, light interacts with auxin during leaf elongation and leaf angle development in young corn seedlings (Fellner et al. 2003), implying photoacclimation. Photosynthetic light-response curves are widely used in models of plant productivity and in characterization of photoacclimation. Fluorescence quenching was used to determine the status of chloroplasts. These determinations were made through repetitive application of saturating light pulses. When recorded with a light-adapted sample, rapid light curve (RLC) data reflect the dependence of the photosynthetic electron transport rate (ETR) on quantum flux density under a given state of light adaptation (Goh et al. 1999). Comparing the RLC of oscowl and WT
(A)

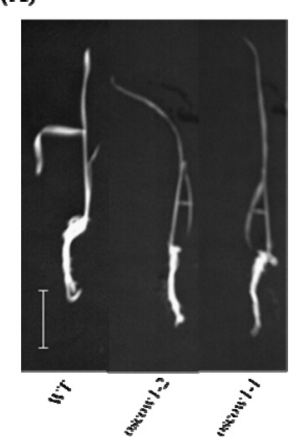

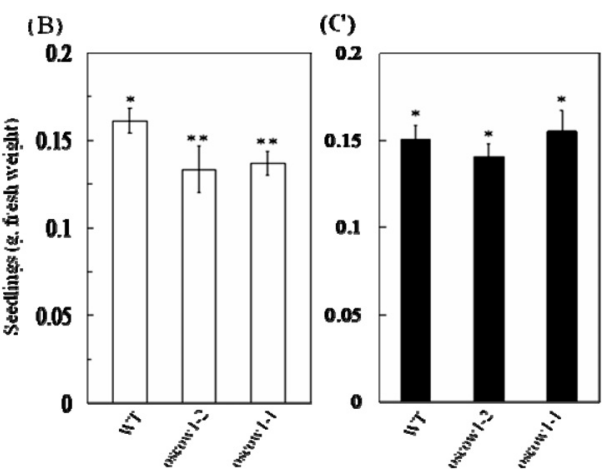

Fig. 1 Growth phenotype of oscow1 mutant seedlings. (A) Ten-day-old plants of the wild-type (WT), oscow1-2, and oscow1-1 plants. Seedlings were grown under white light $\left(100 \mu \mathrm{mol} \mathrm{m} \mathrm{m}^{-2} \mathrm{~s}^{-1}\right)$. Bar, $1.85 \mathrm{~cm}$. Fresh seedling weights were measured 10 days after germination in blue light $\left(40 \mu \mathrm{mol} \mathrm{m} \mathrm{m}^{-1}\right)$ (B) and in the dark (C). Experiments were repeated three times. Values are expressed as means $\pm \operatorname{SE}(n=40)$. Data were square root transformed prior to analysis, and differences in plant growth were compared with a t-test ( $\mathrm{p} \leq 0.05$; SigmaPlot software; Systat Software Inc.). The oscow1-land oscow1-2 indicates homozygous rice plants with either a $\operatorname{Tos} 17$ or T-DNA inserted allele of OsCOW1, respectively (Woo et al. 2007) 
(A)

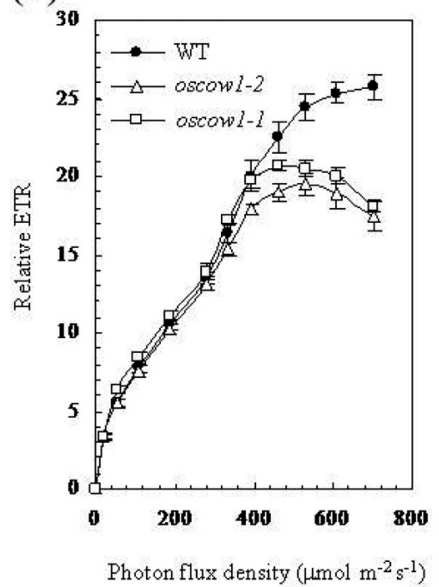

(B)

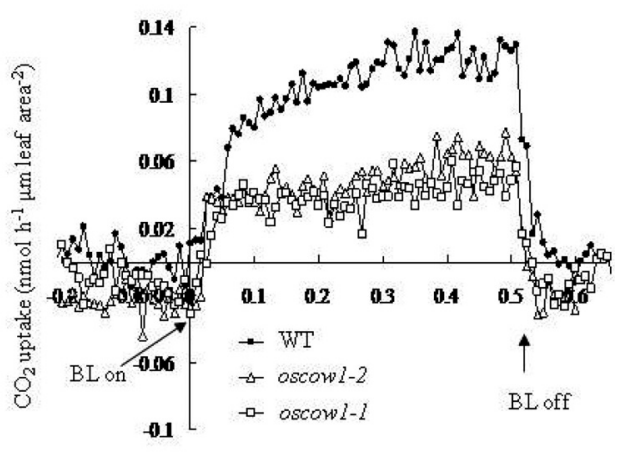

Elaspsed time $(\mathrm{h})$

Fig. 2 Photosynthetic activity of oscowl mutant seedlings. (A) Rapid light response curve showing the relative electron transport rates of WT and oscowl mutant leaves. The measuring light (ML) intensity of photosynthetically-active radiation was $0.8 \mu$ mol $\mathrm{m}^{-2} \mathrm{~s}^{-1}$. Actinic light was applied during consecutive $30 \mathrm{~s}$ periods with stepwise decreases in intensity. The intensity of saturating light was $2990 \mu \mathrm{mol} \mathrm{m} \mathrm{m}^{-2} \mathrm{~s}^{-1}$. At the end of each illumination period, a saturating pulse was applied to assess the effective quantum yield upon which ETR was calculated. Data represent means $\pm \mathrm{SE}(\mathrm{n}=6)$. (B) Changes in $\mathrm{CO}_{2}$ exchange rates in intact leaves of oscowl mutant plants. Closed and open symbols indicate WT and oscowlmutant plants, respectively. Blue light was turned on and off at the times indicated by vertical arrows. Values are expressed as means $(n=3)$. The + and - symbols along the y axes indicate uptake and release of $\mathrm{CO}_{2}$, respectively

plants, we found that the ETR capacity of the former is markedly lower than that of the latter, with half saturations of $185 \mu \mathrm{mol} \mathrm{m} \mathrm{m}^{-2}$ (Fig. 2A). Furthermore, oscowl mutants showed inhibition of ETR over $440 \mu \mathrm{mol} \mathrm{m} \mathrm{m}^{-2} \mathrm{~s}^{-1}$ during periods of increasing activity in the WT, although normal photosynthetic activity was shown at lower light intensities. This suggests partial inhibition of photosynthesis in the mutants at higher light intensities.

For further confirmation of this, we measured leaf gas exchange to compare photosynthetic capacity between oscowl mutants and WT plants. Fast recordings are summarized in Figure 2B. Following saturation under BL conditions $\left(200 \mu \mathrm{mol} \mathrm{m} \mathrm{m}^{-2}\right.$ ), both mutant and WT plants exhibited significant $\mathrm{CO}_{2}$ uptake $6 \mathrm{~min}$ after the lights were turned on, increasing to about $0.04 \mathrm{nmol} \mathrm{h}^{-1} \mu \mathrm{m}^{-2}$ leaf area. However, oscowl mutants did not show any significant increase in $\mathrm{CO}_{2}$ uptake 20 min after the lights were turned on. During this same period, uptake by WT plants had increased up to about $0.15 \mathrm{nmol} \mathrm{h}^{-1} \mu \mathrm{m}^{-2}$ leaf area. In both genotypes, dark treatment resulted in complete recovery of $\mathrm{CO}_{2}$ released from the leaves. The BL-induced $\mathrm{CO}_{2}$ uptake of mutants was about 3 times lower than that of WT plants at the maximum rate. In leaf pigment analysis (Table 2), oscowl mutants and WT plants showed striking differences in the level of carotenoids including beta-carotene, which was about $40 \%$ lower in the mutants $(0.550 \pm 0.009)$ than in the WT $\left(0.895 \pm 0.061 \mu \mathrm{mol} \mathrm{g}\right.$ fresh weight $\left.{ }^{-1}\right)$. Chl a:b ratios of oscowl mutants were $3.84 \pm 0.04$, exceeding those of WT plants. From the results, the different photosynthetic activity of the mutant is due to the lower pigment content, indicating light regulation of pigment formation in the mutant in BL.

It had discovered that expression of the yucca phenotype was differently regulated by different wavelengths of light (Weigel et al. 2000); the yucca mutant was shorter about 25\% than WT when grown in the dark, 3 times taller than WT when grown under white light, no difference from WT when grown under red light, taller than WT when grown under far-red light and blue light. In this study, we investigated the plant growth and photosynthetic activity in the cowl rice mutants when grown under blue light (BL). The plant growth of oscowl mutants was significantly lowered than WT in BL (Fig. 1B). In the dark, it was similar to that of WT seedlings (Fig. 1C). Further treatment with NAA significantly decreased the root growth in all genotypes, showing about $50 \%$ inhibition in the dark (data not shown). This resulted from the decrease in the root to shoot ratios in all plants tested. However, the ratios of root/shoot were largely reduced in the mutants in responding to BL (Table 1) about 2 and 2.5 times decrease 
Table 1 Root and shoot fresh weight and ratios of oscowl mutant seedlings in the absence or presence of NAA under BL

\begin{tabular}{lccc}
\hline & Root $(\mathrm{mg})$ & Shoot $(\mathrm{mg})$ & Root/shoot \\
\hline (- NAA) & & & $0.931 \pm 0.221$ \\
WT & $0.077 \pm 0.006^{\mathrm{a}}$ & $0.087 \pm 0.016^{\mathrm{a}}$ & $0.579 \pm 0.030$ \\
oscow1-1 & $0.055 \pm 0.005^{\mathrm{b}}$ & $0.095 \pm 0.015^{\mathrm{a}}$ & $0.591 \pm 0.108$ \\
oscow1-2 & $0.050 \pm 0.014^{\mathrm{b}}$ & $0.084 \pm 0.013^{\mathrm{a}}$ & $0.927 \pm 0.323$ \\
(+ NAA) & & $0.031 \pm 0.012^{\mathrm{b}}$ & $0.354 \pm 0.048$ \\
WT & $0.025 \pm 0.004^{\mathrm{b}}$ & $0.087 \pm 0.018^{\mathrm{a}}$ & $0.330 \pm 0.015$ \\
\hline oscow1-1 & $0.031 \pm 0.007^{\mathrm{b}}$ & $0.084 \pm 0.020^{\mathrm{a}}$ & \\
\hline
\end{tabular}

Germination occurred in BL $\left(40 \mu \mathrm{mol} \mathrm{m} \mathrm{s}^{-1}\right)$ in the absence and presence of $1 \mu \mathrm{M}$ NAA. Results are means \pm SE ( $\left.=40\right)$ for three replicates, and the different superscript letters in each column indicate statistically significant differences from root and shoot values of the wild-type, respectively $(\mathrm{p} \leq 0.05)$

in the absence and presence of NAA, respectively. In addition, IAA and 2,4-dichlrophenoxyacetic acid (2,4-D) were also examined at $1 \mu \mathrm{M}$, and effects similar to those of NAA in BL were observed (data not shown), even though exogenous auxin analogs are differentially transported by influx and efflux facilitators (Delbarre et al. 1996). At 50 $\mu \mathrm{mol} \mathrm{m} \mathrm{m}^{-2}$ of white light, all genotypes showed similar patterns in root to shoot ratios as well (data not shown). These results indicate the specific regulation of oscowl mutant phenotype by BL, especially root growth.

Previous work with oscowl mutants revealed lower turgor potential and transpiration rate in mature leaves, indicating that oscowl plants are in part water deficient (Woo et al. 2007). This led us to investigate the photosynthetic activity in the mutants, although the shoot growth shows similar pattern in this study (Table 1). We showed that the ETR capacity of the mutant is however markedly lower than that of WT, especially to high light (Figure 2A). Further analysis of pigments showed lower content in Chls and carotenoids (Table 2). This difference demonstrates that the photosynthetic pigment formation is affected by lower water status in the leaves of oscowl mutants in comparison to WT plants, suggesting partial inhibition of photosynthesis in the mutants at higher light intensities. On the other hand, the photosystem II reaction center of all oxygenic organisms is subject to photodamage by high light (i.e., photoinhibition). The inevitable and unpreventable oxidative damage that occurs in the photosystem II reaction center appears to be protected by beta-carotenes (Telfer 2005). Therefore, inhibition of the light response in oscowl mutants might be caused by a decrease in the level of
Table 2 Pigment composition in leaves of the oscow1-1 mutant plants. Plants were grown for $10 \mathrm{~d}$ under BL $\left(40 \mu \mathrm{mol} \mathrm{m}^{-2} \mathrm{~s}^{-1}\right)$

\begin{tabular}{lrr}
\hline \multirow{2}{*}{\multicolumn{1}{c}{ Pigments }} & \multicolumn{1}{c}{ WT } & \multicolumn{1}{c}{ oscowl-1 } \\
\cline { 2 - 3 } & \multicolumn{2}{c}{$\left(\mathrm{mmol} \mathrm{mol} \mathrm{Chl} \mathrm{\textrm { } ^ { - 1 } )}\right.$} \\
\hline Neoxanthin & $156.48 \pm 10.40$ & $65.79 \pm 5.46$ \\
Lutein & $375.63 \pm 25.16$ & $201.23 \pm 5.14$ \\
B-Carotene & $255.14 \pm 17.50$ & $156.85 \pm 2.68$ \\
Violaxanthin & $260.23 \pm 6.47$ & $112.97 \pm 5.07$ \\
Antheraxanthin & $31.93 \pm 1.61$ & $10.47 \pm 2.97$ \\
Zeaxanthin & $0.00 \pm 0.00$ & $0.00 \pm 0.00$ \\
Chl a & $1000.00 \pm 0.00$ & $1000.00 \pm 0.00$ \\
Chl b & $330.98 \pm 3.09$ & $260.57 \pm 2.88$ \\
Chl a/b & $3.02 \pm 0.00$ & $3.84 \pm 0.01$ \\
\hline
\end{tabular}

Values represent means $\pm \operatorname{SE}(n=3)$

beta-carotenes.

In microarray experiment, we identified significant changes in the expression levels of genes involved in cellular processing and signaling and metabolism according to their functioning using Clusters of Orthologous Groups (COG; http://www.ncbi.nlm.nih.gov/COG/) databases (data not shown). In particular, large down-regulation was found in defense mechanisms, signal transduction mechanisms, and secondary metabolics, biosynthesis, transport and metabolism. Given these findings, we suggest that the gene in oscowl plants that results in defective auxin biosynthesis affects the regulation of light responses and associated metabolic processes during plant development.

In conclusion, our results show that the light response of oscowl mutants retards plant growth. Lower root to shoot ratios are caused by $\mathrm{OsCOWI}_{\mathrm{S}}$-mediated auxin biosynthesis, 
which can result, in part, from water deficiency in vegetative tissues during plant development. This suggests that, in rice, growth retardation of oscowl mutants is caused by the partial inhibition of photosynthetic activity resulting from differences in pigment content in high light condition. $\mathrm{H}_{2} \mathrm{O}_{2}$-mediated damage to PS II and I inhibit the repair of photodamage to the photosynthetic machinery (Nishiyama et al. 2001). The degradation of chlorophylls and carotenoids allows $\mathrm{H}_{2} \mathrm{O}_{2}$ damage of the photosystems in $\mathrm{BL}$ signaling and these structural failures reduce the photosynthetic capacity (Goh et al. 2009). Further intensive study is needed to clarify the relationships among photodamage, beta-carotenes and water homeostasis at different light wavelengths.

\section{Acknowledgements}

C.-H. Goh thanks Dr. Young-Min Woo for dividing materials. We would like to thank Young-Jae Eu and Ho-Seung Kim (Busan National University, Korea) for providing an IMAGING-PAM Chlorophyll Fluorometer and pigment analysis. This work was supported by the BK21 program to C.-H.G. and, in part, by a grant from Priority Research Centers Program through the National Research Foundation (NRF) funded by the Ministry of Education, Science and Technology (2010-0029630).

\section{References}

Ballare CL (1999) Keeping up with the neighbors: phytochrome sensing and other signaling mechanisms. Trends Plant Sci 4:97-102

Cheng Y, Dai X, Zhao Y (2006) Auxin biosynthesis by the YUCCA flavin monooxygenases controls the formation of floral organs and vascular tissues in Arabidopsis. Genes Dev 20:1790-1799

Davies PJ (1995) Plant Hormones. In: Davies PJ (ed) Physiology Biochemistry and Molecular Biology. Kluwer Academic, Dordrecht, Netherlands: 1-12

Delbarre A, Muller P, Imhoff V, Guern J (1996) Comparison of mechanisms controlling uptake and accumulation of 2,4-dichlorophenoxyacetic acid, naphthalene-1-acetic acid and indole-3-acetic acid in suspension-cultured tobacco cells. Planta 198:532-541

Fellner M, Horton LA, Cocke AE, Stephens NR, Ford ED,
Volkenburgh EV (2003) Light interacts with auxin during leaf elongation and leaf angle development in young corn seedlings. Planta 216:366-376

Genty B, Briantais JM, Baker NR (1989) The relationship between the quantum yield of photosynthetic electron transport and quenching of chlorophyll fluorescence. Biochim Biophys Acta 990:87-92

Gilmore AM, Yamamoto HY (1991) Resolution of lutein and zeaxanthin using a non-endcapped, lightly carbon-loaded $\mathrm{C}_{18}$ high-performance liquid chromatographic column. J Chromatograph 543:137-145

Goh CH, Schreiber U, Hedrich R (1999) New approach of monitoring changes in chlorophyll $a$ fluorescence of single guard cells and protoplasts in response to physiological stimuli. Plant Cell Environ 22:1057-1070

Goh CH, Jung KH, Roberts SK, McAinsh MR, Hetherington AM, Park YI, Suh K, An G, Nam HG (2004) Mitochondria provide the main source of cytosolic ATP for activation of outward-rectifying $\mathrm{K}^{+}$channels in mesophyll protoplast of chlorophyll-deficient mutant rice seedlings. J Biol Chem 279:6874-6882

Goh CH, Jang S, Jung S, Kim HS, Kang HG, Park YI, Bae HJ, Lee CH, An G (2009) Rice phot1a mutation reduces plant growth by affecting photosynthetic responses to light during early seedling growth. Plant Mol Biol 69:605-661

Imaizumi T, Kadota A, Hasebe M, Wada M (2002) Cryptochrome light signals control development to suppress auxin sensitivity in the moss Physcomitrella patens. Plant Cell 14:373-386 Nishiyma Y, Yamamoto H, Allakhverdiev SI, Inaba M, Yokota A, Murata N (2001) Oxidative stress inhibits the repair of photodamage to the photosynthetic machinery. EMBO J 20:5587-5594

Schreiber U, Bilger W, Neuauer C (1994) Chlorophyll fluorescence as a noninstructive indicator for rapid assessment of in vivo photosynthesis. In: Schulze ED, Caldwell MM (eds). Ecophysiology of Photosynthesis. Ecological studies. Springer press, Berlin: 49-70

Schreiber U, Quayle P, Schmidt S, Escher BI, Mueller JF (2007) Methodology and evaluation of a highly sensitive algae toxicity test based on multiwell chlorophyll fluorescence imaging. Biosens Bioelectron 22:2554-2563

Takano M, Kanegae H, Shinomura T, Miyao A, Hirochika H, Furuya M (2001) Isolation and characterization of rice phytochrome A mutants. Plant Cell 13:521-534

Takemiya A, Inoue S, Doi M, Kinoshita T, Shimazaki K (2005) Phototropins promote plant growth in response to blue light in low light environments. Plant Cell 17:1120-1127 Tao Y, Ferrer JL, Ljung K, Pojer F, Hong F, Long JA, Li L, Moreno JE, Bowman ME, Ivans LJ, Cheng Y, Lim J, Zhao 
Y, Ballaré CL, Sandberg G, Noel JP, Chory J (2008) Rapid synthesis of auxin via a new tryptophan-dependent pathway is required for shade avoidance in plants. Cell 133:164-176

Telfer, A. (2005) Too much light? How beta-carotene protects the photosystem II reaction centre. Photochem Photobiol Sci 4:950-956

Tian Q, Reed JW (2001) Molecular links between light and auxin signaling pathways. J Plant Growth Regul 20:274-280

Weigel D, Ahn JH, Blázquez MA, Borevitz JO, Christensen SK, Fankhauser C, Ferrándiz C, Kardailsky I, Malancharuvil EJ, Neff MM, Nguyen JT, Sato S, Wang ZY, Xia Y, Dixon RA, Harrison MJ, Lamb CJ, Yanofsky MF, Joanne Chory. (2000) Activation tagging in Arabidopsis. Plant Physiol 122:1003-1014

Woodward C, Bemis SM, Hill EJ, Sawa S, Koshiba T, Torii KU (2005) Interaction of auxin and ERECTA in elaborating Arabidopsis inflorescence architecture revealed by the activation tagging of a new member of the YUCCA family putative flavin monooxygenases. Plant Physiol 139:192-203 Woo YM, Park HJ, Su'udi M, Yang JI, Park JJ, Back KW, Park YM, An G (2007) Constitutively wilted 1, a member of the rice YUCCA gene family, is required for maintaining water homeostasis and an appropriate root to shoot ratio. Plant Mol Biol 65:125-136

Yamamoto Y, Kamiya N, Morinaka Y, Matsuoka M, Sazuka T (2007) Auxin biosynthesis by the YUCCA genes in rice. Plant Physiol 143:1362-1371

Zhao Y, Christensen SK, Fankhauser C, Cashman JR, Cohen JD, Weigel D, Chory J (2001) A role for flavin monooxygenaselike enzymes in auxin biosynthesis. Science 291:306-309 Zhuang X, Jiang J, Li J, Ma Q, Xu Y, Xue Y, Xu Z, Chong $\mathrm{K}$ (2006) Over-expression of OsAGAP, an ARF-GAP, interferes with auxin influx, vesicle trafficking and root development. Plant J 48:581-591 